\title{
A new intertidal Brachionus and intrageneric phylogenetic relationships among Brachionus as revealed by allometry and CO1-ITS1 gene analysis
}

\author{
Dae-Sik Hwang ${ }^{1}$, Hans-Uwe Dahms ${ }^{2}$, Heum Gi Park ${ }^{3}$ and Jae-Seong Lee ${ }^{1,4^{*}}$
}

\begin{abstract}
Background: The rotifer genus Brachionus is distributed worldwide along a gradient from freshwater to seawater habitats. This genus is recognized as a suitable organism for testing environmental and evolutionary hypotheses. Here we present the description of a new species and the phylogenetic relationship within the genus Brachionus as revealed by morphometric allometry of two representatives and CO1-ITS1 gene analysis of five representatives belonging to Brachionus distributed in the fresh and seawaters of Korea, Japan, and China.

Results: Similarities of populations were studied using nuclear rDNA ITS1 sequences from Brachionus spp. collected from different geographical areas of Far East Asia. The phylogeographic analysis of nuclear DNA ITS1 and mitochondrial $\mathrm{CO} 1$ sequences showed that Brachionus from South Korea formed five distinct clades according to their geographic origin. Interspecific differences suggest that Brachionus species established on conventional morphological characters also forms five separate clades. When ITS1-CO1 of the Asian specimens was compared with representatives of Brachionus worldwide, a high genotypic similarity was found. However, they slightly differed between localities.
\end{abstract}

Conclusions: This study sets a first step for an integrative morphological and molecular characterization of the diversity contained within the ecologically and economically important rotifer genus Brachionus.

Keywords: Rotifera; Brachionus; rDNA ITS1; CO1; Morphometry; Phylogenetics

\section{Background}

Rotifers comprise several groups such as the marine Seisonida, Monogononta, and parthenogenetic Bdelloidea. Among them, the monogonont genus Brachionus spp. is widely distributed in marine and freshwaters worldwide (Hagiwara et al. 1995; Gómez and Snell 1996). Rotifers are considered as model species in diverse research areas such as aquaculture, ecophysiology, and ecotoxicology (Snell and Janssen 1995; Lubzens et al. 2001; Dahms et al. 2011).

The Brachionus species described formally here as Brachionus koreanus sp. nov. was studied before as a nomen nudum. Hwang et al. (2013) reported the complete mitochondrial DNA from Brachionus plicatilis

\footnotetext{
* Correspondence: jslee2@hanyang.ac.kr

'Department of Molecular and Environmental Bioscience, Graduate School, Hanyang University, Seoul 133-791, South Korea

${ }^{4}$ Department of Chemistry, College of Natural Sciences, Hanyang University, Seoul 133-791, South Korea

Full list of author information is available at the end of the article
}

and a Korean population here described as B. koreanus sp. nov. Concerning genetic approaches, Suga et al. (2008) described the mitogenome of B. plicatilis from Japan. The mitochondrial DNA of both species consisted of two circular mitochondrial genomes with a rearrangement of tRNA-Cys between tRNA-Arg and tRNA-Ile, whereas other protein-coding genes, tRNAs and rDNAs, were conserved in their placement between the two species. Min and Park (2009) reported the complete mitochondrial genome sequence of Rotaria rotatoria (Bdelloidea: Rotifera: Syndermata), having a single circular mitochondrial genome. Thus, the structure of the complete mitochondrial genome and the gene order is not conserved among different rotifer taxa, as shown in Brachionus and the bdelloid R. rotatoria. As for the closest taxon to the Rotifera, the Acanthocephala, Steinauer et al. (2007) showed a difference of the mitogenome of the acanthocephalan Leptorhynchoides thecatus. 


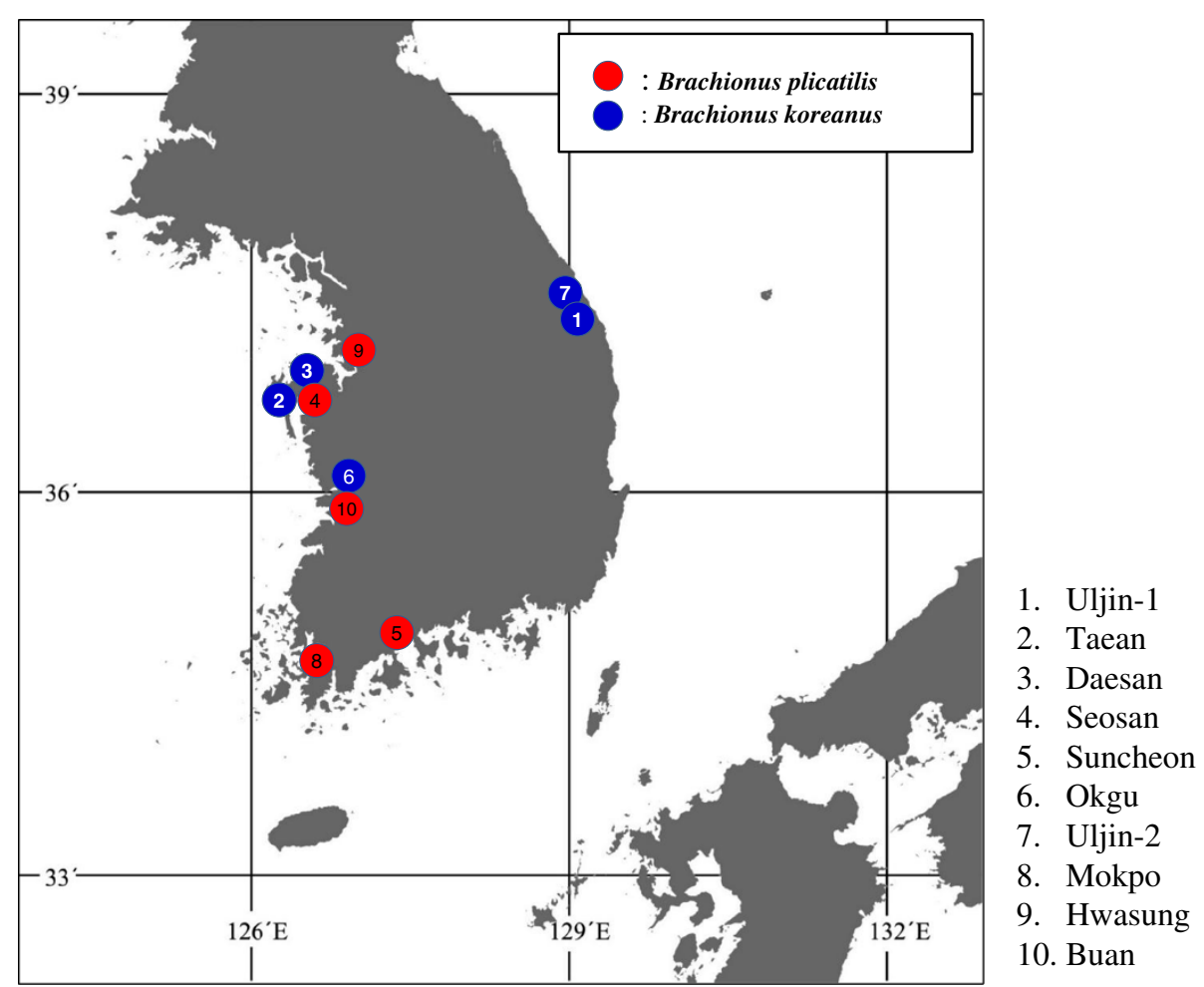

Figure 1 Geographic distribution of sampling sites of $\boldsymbol{B}$. koreanus and $\boldsymbol{B}$. plicatilis. The figure shows the geographic distribution in the Far East western Asian study area.

Morphological similarity (i.e., cryptic or sibling species) is recognized in several organisms (Serra et al. 1998; Chullasorn et al. 2009). This holds also for rotifers where several species are genetically distinct but reveal only little morphological dissimilarity (Walker 1981). Regarding the morphological taxonomy of Brachionus, there is little information available, so misidentification might occur due to morphological ambiguity. In the case of Brachionus, no geophylogenetic analysis of representatives of Brachionus has been performed using mitochondrial and rDNA sequences. In this study, we analyzed the molecular phylogenetic relationships of rotifers, including five representatives of Brachionus (i.e., B. plicatilis, Brachionus manjavacas, Brachionus rotundiformis, B. koreanus, and Brachionus

Table 1 Morphometric characteristics of two Brachionus species

\begin{tabular}{|c|c|c|c|c|c|c|c|c|c|c|}
\hline \multirow[t]{2}{*}{ Strain } & & \multicolumn{9}{|c|}{ Mean of body length $(\mu \mathrm{m})$} \\
\hline & & $a$ & $b$ & $c$ & $d$ & $e$ & $f$ & $g$ & $h$ & $i$ \\
\hline \multirow[t]{5}{*}{ B. koreanus } & Uljin-1 (S) & 196.07 & 106.46 & 151.09 & 17.53 & 21.59 & 22.91 & 12.40 & 15.16 & 108.15 \\
\hline & Daesan & 192.26 & 90.61 & 139.13 & 17.56 & 18.50 & 20.49 & 11.02 & 13.72 & 91.93 \\
\hline & Okgu & 194.59 & 97.14 & 146.31 & 18.39 & 19.25 & 21.93 & 11.83 & 14.37 & 99.53 \\
\hline & Uljin-2 (L) & 213.40 & 95.25 & 156.35 & 17.56 & 20.09 & 20.32 & 11.90 & 11.77 & 101.96 \\
\hline & Taean & 212.46 & 99.45 & 162.46 & 20.17 & 20.25 & 19.62 & 12.57 & 13.67 & 102.34 \\
\hline \multirow[t]{7}{*}{ B. plicatilis } & China & 276.22 & 127.55 & 210.38 & 29.90 & 26.41 & 26.17 & 14.83 & 16.67 & 139.65 \\
\hline & Hwasung & 306.13 & 130.89 & 239.03 & 30.45 & 26.13 & 28.55 & 14.03 & 13.17 & 148.90 \\
\hline & Mokpo & 277.25 & 119.98 & 202.01 & 28.53 & 23.78 & 27.83 & 13.38 & 15.98 & 129.33 \\
\hline & Buan & 303.54 & 136.50 & 229.79 & 28.62 & 29.17 & 29.38 & 15.30 & 16.14 & 146.22 \\
\hline & Seosan & 329.32 & 123.29 & 249.24 & 22.29 & 25.19 & 26.41 & 12.79 & 13.88 & 147.21 \\
\hline & Suncheon & 300.24 & 122.26 & 218.95 & 30.46 & 25.62 & 26.38 & 14.16 & 14.43 & 133.31 \\
\hline & Japan & 256.14 & 123.14 & 189.32 & 27.53 & 23.36 & 24.79 & 12.77 & 16.32 & 134.17 \\
\hline
\end{tabular}


ibericus) that were inferred from rDNA ITS1 and mitochondrial CO1 sequences. Finally, we investigated the biogeography of Asian marine Brachionus spp. (B. plicatilis and $B$. koreanus sp. nov.) using morphometric allometry. These findings were compared with those from ITS1 and mitochondrial sequences.

\section{Methods}

\section{Sample collection}

The organisms used in this study were sampled from different locations as summarized in Figure 1. After sampling, rotifers were concentrated through filtration onto a $100-\mu \mathrm{m}$ pore-sized mesh and preserved in $70 \%$ EtOH. The identities of species were initially checked by stereomicroscopy and further verified by genomic tools used herein (mt COI and rDNA ITS1 sequence comparison). Samples were stored at $4^{\circ} \mathrm{C}$ until used. A total of 12 clones from the two sibling species of the genus Brachionus were investigated. The clones were obtained from the rotifer culture collection at the Hanyang University in Seoul. They consisted of parthenogenetically cultured strains based on the isolation of single amictic females. They were collected from several localities (Table 1). All the specimens used for the morphological description and morphometric analysis came from stock cultures that were also used for the morphometric and genomic analysis.

\section{Culture conditions}

Stock cultures were maintained at $25^{\circ} \mathrm{C}$ under a lightdark 12:12 h photoperiod, and salinity was 15 PSU. Animals were fed with the green algae Chlorella sp. (approximately $6 \times 10^{4}$ cells $/ \mathrm{mL}$ ) and maintained at constant light conditions, and the medium was renewed weekly for at least 1 month prior to experimentation. Saline water was made with commercial sea salt (TetraMarine Salt Pro, Tetra ${ }^{\mathrm{Tm}}$, Columbus, OH, USA).

\section{Morphology, morphometry, and statistical analyses}

Morphometric values were compared using animals of the same age. For each clone, several amictic eggbearing females were taken from exponentially growing stock cultures. For each clone, ten triplicates (a total of 30 individuals) of fixed amictic egg-bearing females (48 h old) were randomly chosen, and a photo was taken under a fluorescence microscope before measurements. Nine characters of the lorica were measured under a fluorescent microscope $(\times 20)$ with the measurement software MetaMorph (version 7.6). Seven of the characters used in the analysis (Figure 2) were selected on the basis of $\mathrm{Fu}$ et al. (1991), and two others were used in addition as we considered them to be of taxonomic importance.

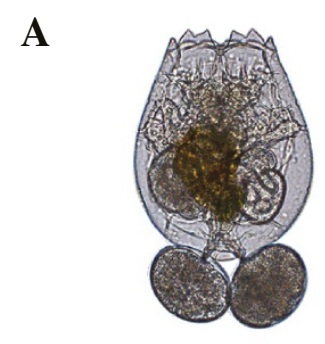

B. plicatilis Hwasung

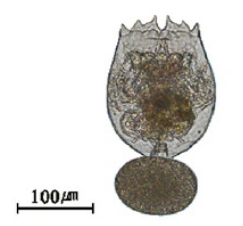

B. koreanus Uljin-1
B

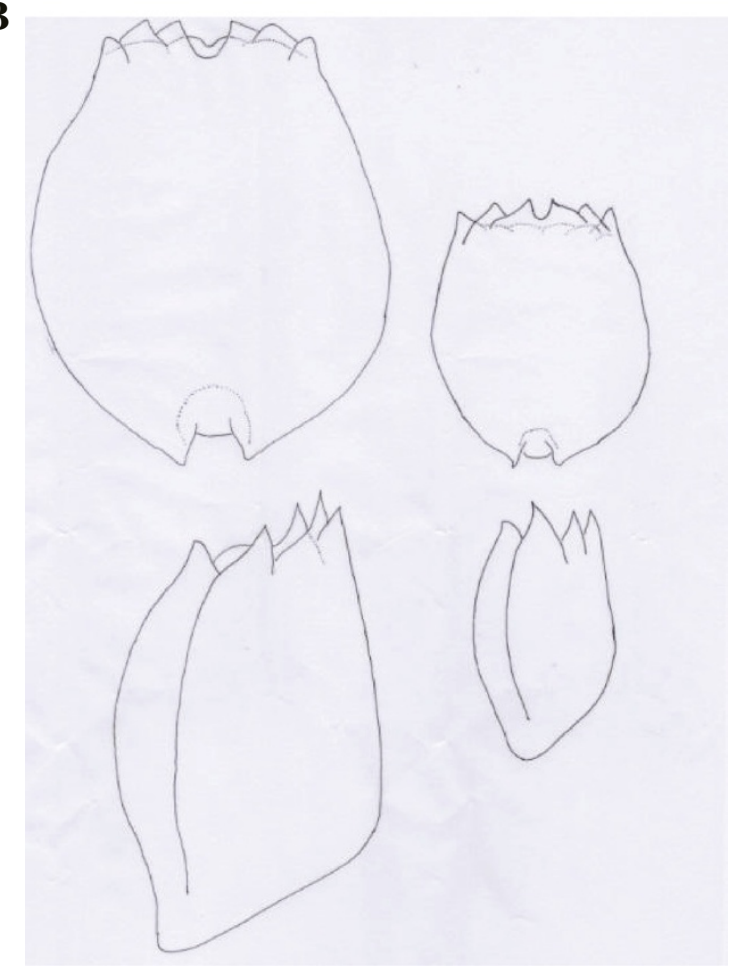

B. plicatilis Hwasung

B. koreanus Uljin-1

Figure 2 Characteristics and measurements of the lorica of Brachionus spp. (A) Photomicrography. (B) Drawing. Characters follow Fu et al. (1991).

All statistical analyses were performed using the SPSS program (release 10. SPSS Inc., Chicago, IL, USA). Two stepwise discriminating analyses were performed to discriminate among strains on previously log-transformed (Ln) measurements. According to the method of $\mathrm{Fu}$ et al. (1991) (Figure 2), we analyzed nine characters and used six characters to distinguish two Brachionus species (12 clones) as shown before by Ciros-Pérez et al. (2001) (Figure 3). Six of the characters measured include lorica length $(a)$, lorica shape $(c / a$ and $i / a)$, the relative length of dorsolateral spines 2 and $3(g / h)$, and length of spine 3 in relation to lorica length $(h / a)$ (Figure 2). After measurement, one-way ANOVA was conducted to compare morphological differences among two sibling species (B. plicatilis and 

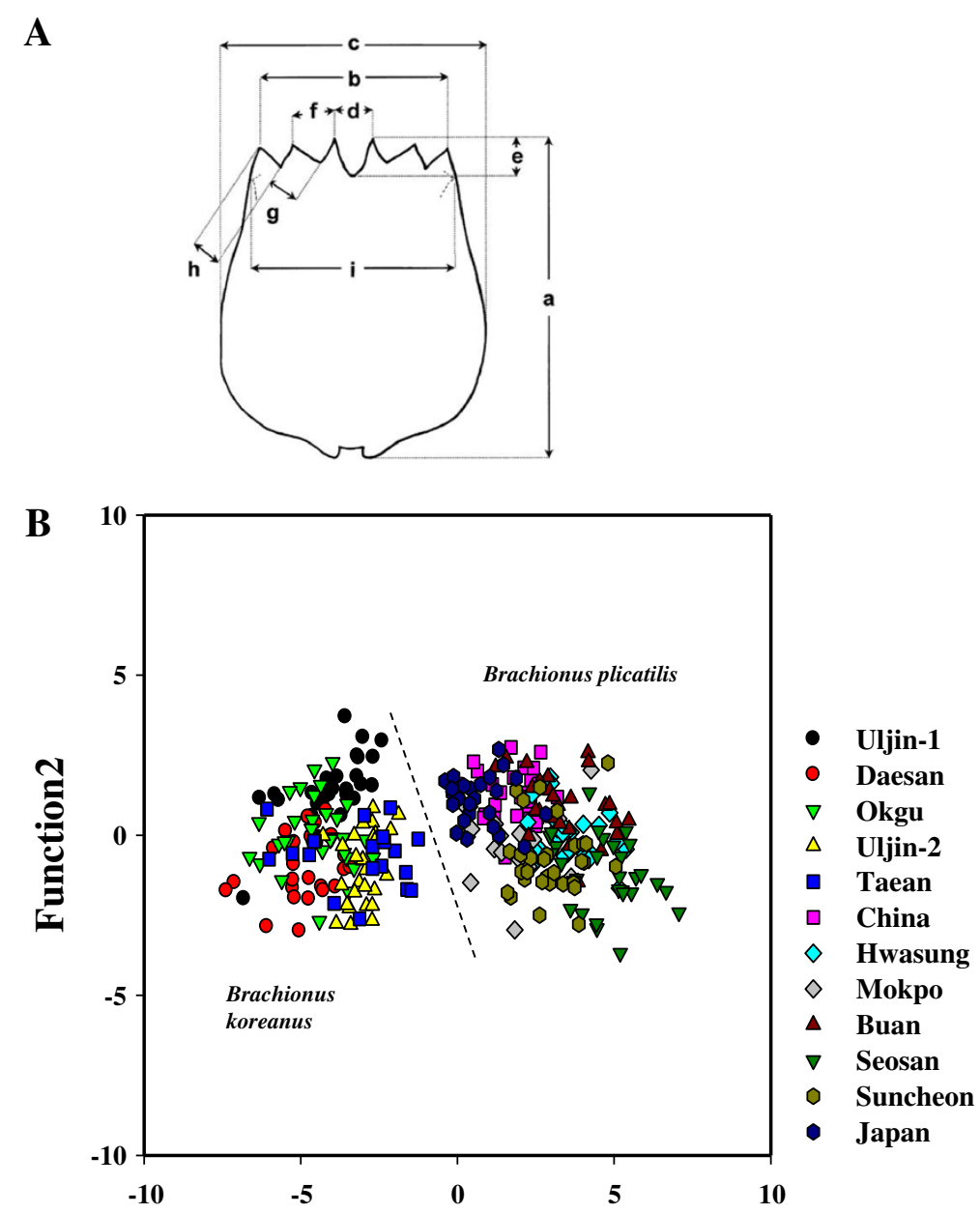

Function1

Figure 3 Scatterplot of the measured individuals in the space defined by two canonical discriminant functions. (A) Measurement of rotifer characterization. (B) Scatter-plot analysis of measured characters. The functions were retrieved from discriminant stepwise analyses of several lorica measurements of individuals belonging to two putative Brachionus spp. and 12 clones. We modified the method of Fu et al. (1991) according to Ciros-Pérez et al. (2001).

B. koreanus). When differences were found, post-hoc (multiple comparisons among means) Student-NewmanKeuls (Sokal and Rohlf 1969) tests were carried out.

\section{CO1 and ITS1 rDNA sequences from geographic samples}

For CO1 and ITS1 amplification from different geographical samples, we used pooled individuals of Brachionus specimens as DNA templates without genomic DNA extraction. CO1 and ITS1 rDNA was amplified by conventional polymerase chain reaction (PCR) protocols with its $\mathrm{CO} 1$ and ITS1 targeting primers (for CO1 gene, Br-CO1-LCO1490, 5'-GGT CAA CAA ATC ATA AAG ATA TTG G-3', Br-CO1-HCO2198, 5' -TAA ACT TCA GGG TGA CCA AAA AAT CA-3', 812 bp; for ITS1, Br-ITS1-III, 5'-CAC ACC GCC CGT CGC TAC TAC CGA TTG-3' and Br-ITS1-VIII, 5'-GTG
CGT TCG AAG TGT CGA TGA TCA A-3', 596 bp). PCR thermocycling was as follows: $95^{\circ} \mathrm{C}$ for $5 \mathrm{~min}, 35$ cycles of denaturation at $95^{\circ} \mathrm{C}$ for $20 \mathrm{~s}$, annealing at $55^{\circ} \mathrm{C}$ for $30 \mathrm{~s}$ and extension at $72^{\circ} \mathrm{C}$ for $60 \mathrm{~s}$, and a final extension at $72^{\circ} \mathrm{C}$ for $5 \mathrm{~min}$. PCR products from 12 geographic samples were subcloned into a pCR2.1 TA cloning vector (Invitrogen, Carlsbad, CA, USA), and all the subcloned DNAs were sequenced according to the manufacturer's suggested protocol with commercial primers (e.g., T7 and M13R).

Editing and contig assembly of the rDNA sequences were carried out with Sequencher 4.1.4 (Gene Codes, Ann Arbor, MI, USA). All sequences determined here have been deposited at GenBank ([GenBank:GU987061-GU987072] for the CO1 sequence and [GenBank:GU987073-GU987084] for the ITS1 sequence). 


\section{Mitochondrial $\mathrm{CO} 1$ sequence analyses}

For genetic variation in five Brachionus spp., mitochondrial $\mathrm{CO} 1$ sequences (see 12 isolates in Table 1) were subjected to a similarity analysis. The ITS1 and CO1 sequences were individually aligned with ClustalW ver.1.8 (Thompson et al. 1994). To distinguish five Brachionus species, we used six domains of the $\mathrm{CO} 1$ gene as shown in Vasileiadou et al. (2009).

\section{Phylogeography of Brachionus spp. inferred from CO1 and ITS1 rDNA}

The phylogeography of Asian Brachionus spp. was studied with mitochondrial CO1 (812 bp) and nuclear ITS1 rDNA (596 bp) sequences. To place the identified CO1ITS1 rDNA $(1,408 \mathrm{bp})$ in the phylogenetic tree, we aligned them with those of other species at nucleotide level by ClustalX 1.83. Gaps and missing data matrix were excluded from the analysis. The generated data matrix (932 bp) was converted to Nexus format, and the data matrix was analyzed with the Mr. Bayes v3.1.2 program (Huelsenbeck and Ronquist 2001) using the general time-reversible model. A total of 1 million generations with the Markov chain Monte Carlo process were conducted, and the sampling frequency was assigned as every 100 generations. After analysis, the first 10,000 generations were deleted as the burn-in process, and a consensus tree was constructed.

\section{Results}

\section{Parthenogenetic female of $B$. koreanus sp. nov}

Type locality. The parthogenetic female of B. koreanus sp. nov was collected from Uljin-1 (S), South Korea.

Holotype. A parthenogenetic female was deposited at the Department of Invertebrate Zoology, National Museum of Natural History, Smithsonian Institution, Washington, D.C. with the following catalogue number: USNM 1115523. About 100 allotypes were deposited at the same institution in a vial preserved in $70 \%$ ethanol/ glycerin (USNM 1115524). The lorica was smooth and pear shaped (Figure 2) with ventral and dorsal plates fused dorsally and laterally. The U-like sinus carries three pairs of spines at each side laterally. All spines are triangular and dissimilar in length; the outer and inner spines are longer than the middle one. The outer spine has a sigmoid outer margin. The anterior ventral margin of the lorica with two pairs of rounded lobules was located at both sides of the slender sinus. Inner lobes show a narrower base than the outer one. The lateral antennae are pointing medially. The foot opening is located subterminally on the ventral plate. The trophi are symmetrical and lobular. The fulcrum is hollow, short, and truncated in shape. The rami are rectangular with a ventral flat surface. The unci are plate-like and carry six solid ridges.
Table 2 Stepwise discriminant analyses of Brachionus body measurements

\begin{tabular}{lccccc}
\hline & \multicolumn{2}{c}{ Function 1 } & & \multicolumn{2}{c}{ Function 2 } \\
\cline { 2 - 3 } \cline { 5 - 6 } & Coefficient & Correlation & & Coefficient & Correlation \\
\hline $\operatorname{Ln}(a)$ & 0.946 & $0.971^{\text {a }}$ & & -0.557 & -0.155 \\
$\operatorname{Ln}(b)$ & - & - & - & - \\
$\operatorname{Ln}(c)$ & -0.084 & $0.834^{\mathrm{a}}$ & -0.213 & 0.045 \\
$\operatorname{Ln}(d)$ & - & - & & - & - \\
$\operatorname{Ln}(e)$ & 0.071 & 0.330 & & 0.360 & 0.465 \\
$\operatorname{Ln}(f)$ & - & - & & - & - \\
$\operatorname{Ln}(g)$ & -0.138 & 0.148 & & 0.250 & 0.305 \\
$\operatorname{Ln}(h)$ & 0.042 & 0.044 & & 0.335 & 0.469 \\
$\operatorname{Ln}(i)$ & 0.236 & $0.621^{\mathrm{a}}$ & & 0.883 & 0.592 \\
Eigenvalue & 12.642 & & & 0.870 & \\
\% variance & 88.9 & & & 6.1 & \\
\hline
\end{tabular}

Only values for the first two canonical functions (Functions 1 and 2) of each discriminant analysis are shown. ${ }^{\text {a }}$ Statistically significant based on morphological characters of the lorica between B. koreanus and B. plicatilis to separate two different species under morphometrical discriminant analysis.

Differential diagnosis. $B$. koreanus sp. nov. differs from its sibling B. plicatilis Müeller in the following: The three pairs of anterodorsal spines are different in length; the outer and inner spines are longer than the middle one. All spines are triangular in shape, but the outer one has a sigmoid outer margin. Resting eggs are ovoid, showing a smooth surface but carry many more pores all over

Table 3 Mean (SE) of body length and four body ratios for the two siblings $B$. plicatilis and $B$. koreanus

\begin{tabular}{lccccc}
\hline & \multicolumn{5}{c}{ Morphometric variable } \\
\cline { 2 - 6 } & $\boldsymbol{a}$ & $\boldsymbol{c} / \boldsymbol{a}$ & $\boldsymbol{i} / \boldsymbol{a}$ & $\boldsymbol{h} / \boldsymbol{a}$ & $\boldsymbol{g} / \boldsymbol{h}$ \\
\hline B. koreanus & & & & & \\
AVE & 201.04 & 0.7481 & $0.5021^{\mathrm{a}}$ & $0.0690^{\mathrm{a}}$ & $0.8873^{\mathrm{a}}$ \\
Uljin-1 (S) & 196.07 & 0.7706 & 0.5516 & 0.0773 & 0.8178 \\
Daesan & 192.26 & 0.7235 & 0.4783 & 0.0715 & 0.8235 \\
Okgu & 194.59 & 0.7515 & 0.5118 & 0.0742 & 0.8280 \\
Uljin-2 (L) & 213.40 & 0.7331 & 0.4783 & 0.0552 & 1.0190 \\
Taean & 212.46 & 0.7649 & 0.4828 & 0.0652 & 0.9523 \\
B. plicatilis & & & & & \\
AVE & 293.89 & 0.7514 & $0.4797^{\mathrm{a}}$ & $0.0524^{\mathrm{a}}$ & $0.9516^{\mathrm{a}}$ \\
China & 276.22 & 0.7618 & 0.5059 & 0.0605 & 0.9165 \\
Hwasung & 306.13 & 0.7808 & 0.4873 & 0.0431 & 1.0904 \\
Mokpo & 277.25 & 0.7281 & 0.4667 & 0.0580 & 0.8537 \\
Buan & 303.54 & 0.7570 & 0.4829 & 0.0534 & 0.9762 \\
Seosan & 329.32 & 0.7573 & 0.4486 & 0.0422 & 0.9614 \\
Suncheon & 300.24 & 0.7289 & 0.4445 & 0.0483 & 1.0192 \\
Japan & 256.14 & 0.7400 & 0.5246 & 0.0638 & 0.8082 \\
\hline
\end{tabular}

${ }^{a}$ Statistically significant based on morphological characters of the lorica between $B$. koreanus and $B$. plicatilis to separate two different species under morphometrical discriminant analysis. 
their surface than in B. plicatilis. Body size is substantially smaller than in B. plicatilis (see morphometry below).

\section{Morphometric measurements}

Morphological characters of the lorica (Figure 2) were chosen for the analyses. Characteristics and measurements of the lorica characters of Brachionus spp. follow $\mathrm{Fu}$ et al. (1991). Mean body length and four body ratios for different populations of B. koreanus sp. nov. and B. plicatilis are provided in Tables 1,2 , and 3 . Morphometrical discriminant analysis was following the method of Ciros-Pérez et al. (2001) to clearly distinguish the morphometry as shown in Figure 3. Function 1 is largely correlated not only with the two major body measurements ( $a$ and $c ; r=0.971$ and 0.834 , respectively) but also with the head aperture (i.e., $i, r=0.621)$. Function 2 is correlated with traits associated with spines and represented by variables $e$ (dorsal sinus length; $r=0.465$ ) and $h$ (spine 3 length; $r=0.469$ ).

\section{Comparison of mitochondrial $\mathrm{CO} 1$ sequences between five Brachionus species}

To analyze the mitochondrial CO1 gene from five Brachionus species, we amplified partial CO1 sequence (812 bp) using conserved primers and compared six specific regions that are able to distinguish six species belonging to Brachionus. As shown in Figure 4, we found several alleles from five rotifer species. Of them, $B$. koreanus sp. nov. was clearly isolated from others.

\section{Phylogenetic relationships among Brachionus spp. as inferred from CO1 and ITS1 rDNA}

Mitochondrial CO1 and nuclear rDNA sequences are useful in molecular systematics to estimate genetic diversity and phylogenetic relationships between taxa (Kellogg et al. 1996). Of these, nuclear rDNAs were particularly applied for delineating higher taxon levels, e.g., families and orders due to the high level of conservation among these sequences. In contrast, ITS regions are considered to be useful in defining interspecific differences, as they are less subject to functional constraints and would evolve more rapidly. Therefore, we investigated rotifer phylogeny using ITS1 along with CO1 gene from the rotifer genus Brachionus. Using CO1 and ITS1, we reconstructed a phylogenetic tree of six species belonging to the genus Brachionus (Figure 5).

To get a cue about large-scale biogeographic intraspecific variation, we investigated CO1-ITS1 sequences of 45 Brachionus populations collected from geographical areas as disjunct as Korea, China, and Japan as well as CO1-ITS1 sequences from GenBank (Figure 1, Table 4).

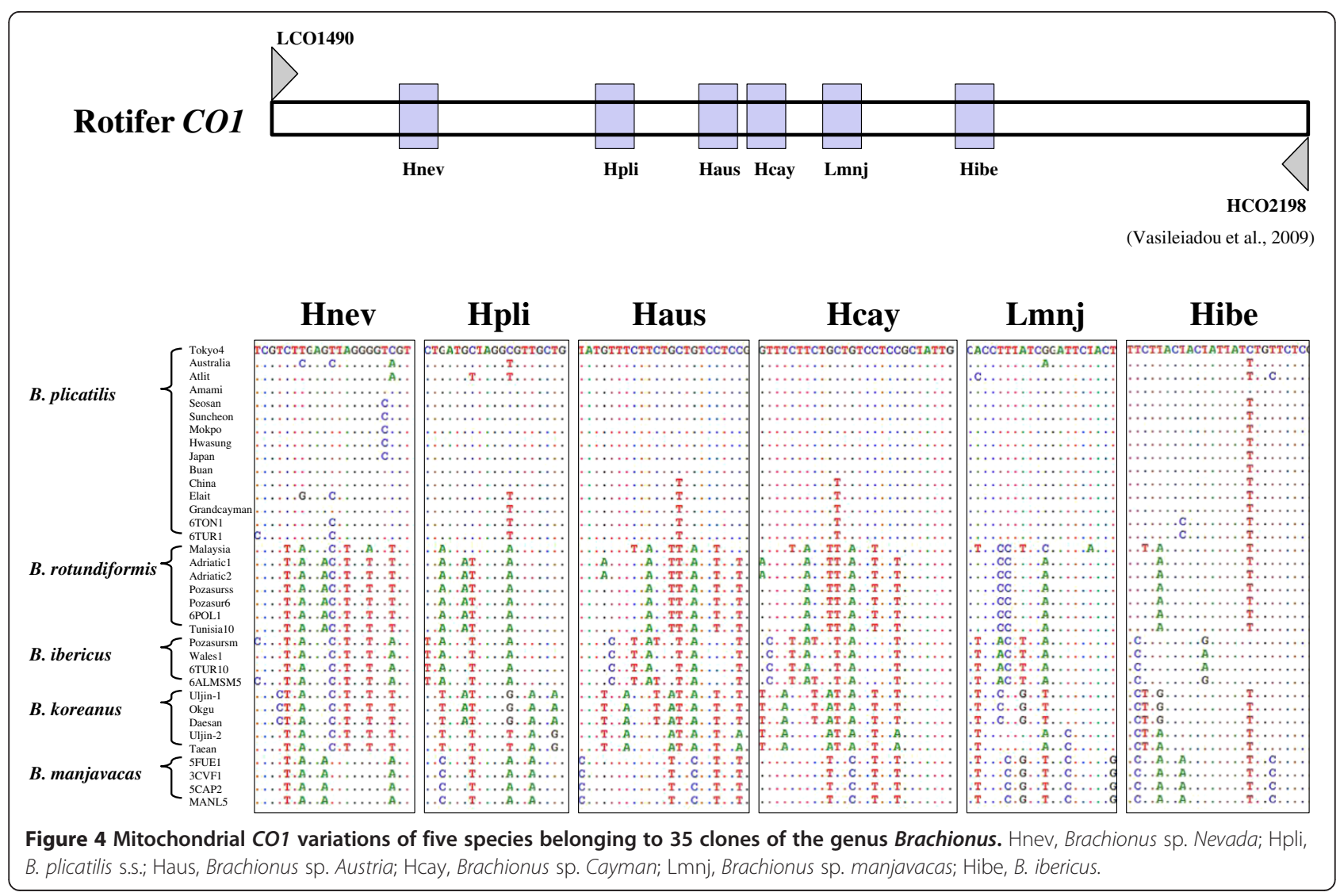




\section{CO1 + ITS1}

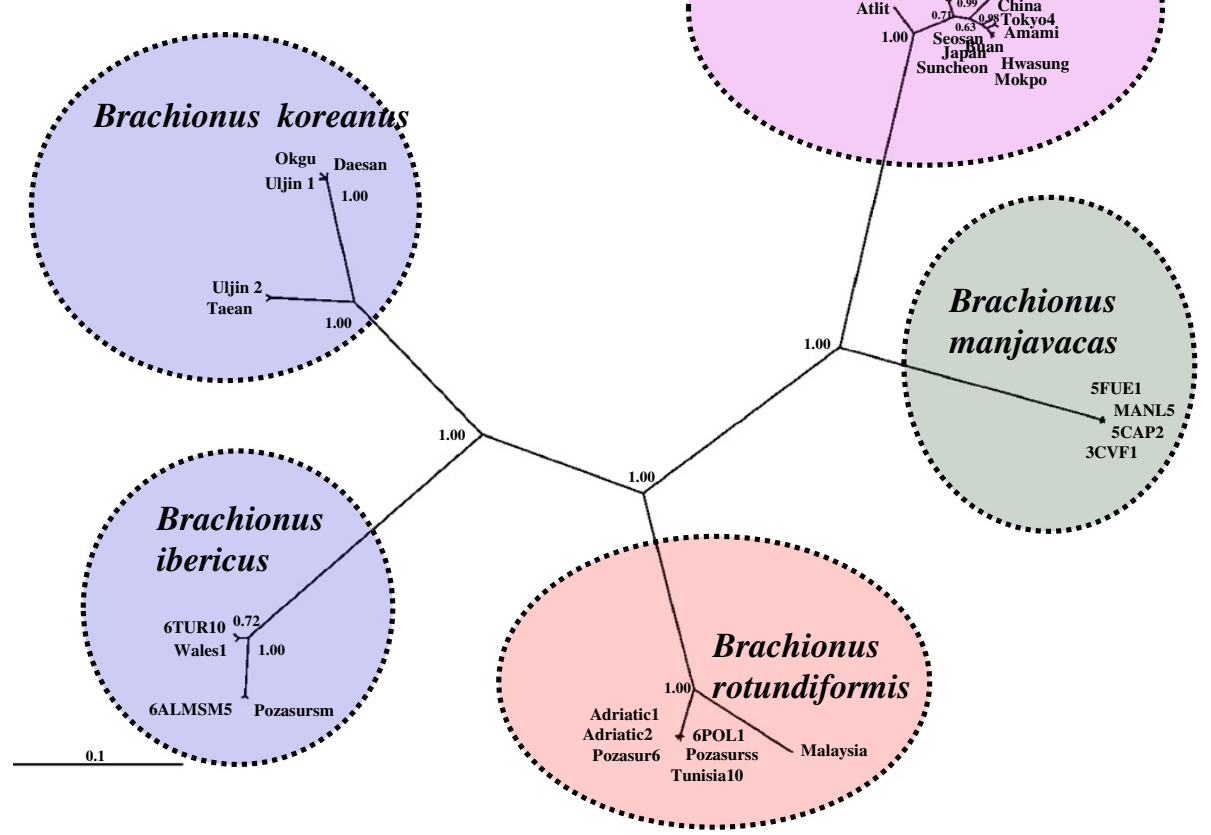

Figure 5 Molecular phylogenetic tree of Brachionus spp. inferred from CO1-ITS1 sequences using Bayesian method.

Molecular analyses of the geographic samples showed that $\mathrm{CO} 1$ sequences were quite different between these populations (Figure 4).

\section{Comparison of complete mitochondrial DNA between B. plicatilis and B. koreanus}

We sequenced the complete mitochondrial genome from the rotifer B. koreanus, which consisted of two circular forms of mitochondrial DNA as shown in Figure 6A, and compared these with those of its supposedly closest related species, B. plicatilis (Figure 6B). The organization of both mitochondrial genomes was almost identical, but there was one rearrangement of $t R N A-C y s$ between $t R N A$ arg and $t R N A$-ile.

\section{Discussion}

Our morphometrical discriminant analysis following the method of Ciros-Pérez et al. (2001) clearly distinguished the morphometries of the different species. As Ciros-Pérez et al. (2001) mentioned, this analysis was much more efficient in separating species groups of rotifers. Hence, we could separate three groups, each corresponding to one of the two sibling species. The most reliable measurements to differentiate between species are those regarding body size and general body shape, and the relative length of the spines.
A major problem with the systematics of the genus Brachionus seems to be the unresolved status of several sibling species clusters (Gómez and Snell 1996; Serra et al. 1998). The species involved might have a more restricted distribution than previously thought (Sudzuki 1987). Several similar strains were classified although no type material is available for most of the species belonging to Brachionus. The present study employing both morphological and molecular data is meant as a reference base for future comparative studies. As for the $B$. plicatilis species complex, Segers (1995) proposed the use of B. plicatilis Müller (1976) and B. rotundiformis Tschugunoff (1921) as the correct names for the formerly designated S- and L-morphotypes, respectively. Although the distinction of S- vs. L-type might be of sound systematic importance, this does not mean that only two species belong to this species complex as emphasized by Ciros-Pérez et al. (2001). In this sense, the analysis based on populations (several strains belonging to each population) rather than on single strains (each belonging to a different population) will provide more information for the delineation of species within this genus.

As for the mitochondrial CO1 gene from five Brachionus species, we found several alleles from five rotifer species (Figure 4). Of them, B. koreanus sp. nov. was clearly isolated from others. Vasileiadou et al. (2009) 
Table 4 Characteristics of Brachionus species, including other Rotifera, used in this study and DNA sequence accession numbers

\begin{tabular}{|c|c|c|c|c|}
\hline \multirow[t]{2}{*}{ Genus } & \multirow[t]{2}{*}{ Species } & \multirow[t]{2}{*}{ Strain } & \multicolumn{2}{|c|}{ Accession number } \\
\hline & & & $\mathrm{CO1}$ & ITS1 \\
\hline \multirow[t]{40}{*}{ Brachionus } & B. plicatilis & Tokyo4 & [GenBank:AY785177.1] & [GenBank:AY772097.1] \\
\hline & & Australia1 & [GenBank:AF387244.1] & [GenBank:AF387206.1] \\
\hline & & Caperomaine2 & [GenBank:AY785233.1] & [GenBank:AY772155.1] \\
\hline & & Atlit & [GenBank:AY785190.1] & [GenBank:AY772110.1] \\
\hline & & Amami & [GenBank:AY785174.1] & [GenBank:AY772094.1] \\
\hline & & Austria4 & [GenBank:AY785200.1] & [GenBank:AY772120.1] \\
\hline & & Elait & [GenBank:AY785188.1] & [GenBank:AY772108.1] \\
\hline & & GrandCayman2 & [GenBank:AY785189.1] & [GenBank:AY772109.1] \\
\hline & & 6TON1 & [GenBank:AF266858.1] & [GenBank:AF387199.1] \\
\hline & & 6TUR1 & [GenBank:AF266859.1] & [GenBank:AF387197.1] \\
\hline & & Seaazov & [GenBank:AY785194.1] & [GenBank:AY772114.1] \\
\hline & & Mortlock1 & [GenBank:AY785227.1] & [GenBank:AY772149.1] \\
\hline & & Seosan & [GenBank:GU987064] & [GenBank:GU987076] \\
\hline & & Suncheon & [GenBank:GU987065] & [GenBank:GU987077] \\
\hline & & China & [GenBank:GU987066] & [GenBank:GU987078] \\
\hline & & Mokpo & [GenBank:GU987069] & [GenBank:GU987081] \\
\hline & & Hwasung & [GenBank:GU987070] & [GenBank:GU987082] \\
\hline & & Japan & [GenBank:GU987071] & [GenBank:GU987083] \\
\hline & & Buan & [GenBank:GU987072] & [GenBank:GU987084] \\
\hline & B. rotundiformis & Malaysia & [GenBank:AY785225.1] & [GenBank:AY772147.1] \\
\hline & & Adriatic1 & [GenBank:AY785223.1] & [GenBank:AY772145.1] \\
\hline & & Adriatic2 & [GenBank:AY785224.1] & [GenBank:AY772146.1] \\
\hline & & Pozasurss & [GenBank:AY785222.1] & [GenBank:AY772144.1] \\
\hline & & Pozasur6 & [GenBank:AY785221.1] & [GenBank:AY772143.1] \\
\hline & & 6POL1 & [GenBank:AF387289.1] & [GenBank:AF387239.1] \\
\hline & & Tunisia10 & [GenBank:AF387288.1] & [GenBank:AF387240.1] \\
\hline & B. calyciflorus & AHNU-Rotifer-T8 & [GenBank:FJ826939.1] & [GenBank:GU321460.1] \\
\hline & & AHNU-Rotifer-T5 & [GenBank:FJ826938.1] & [GenBank:GU321457] \\
\hline & & AHNU-Rotifer-W21 & [GenBank:FJ827006.1] & [GenBank:FJ937603] \\
\hline & & Florida & [GenBank:DQ071673.1] & [GenBank:DQ071669.1] \\
\hline & & Australia & [GenBank:DQ071675.1] & [GenBank:DQ071671.1] \\
\hline & & Texas & [GenBank:DQ071674.1] & [GenBank:DQ071670.1] \\
\hline & B. ibericus & Pozasursm & [GenBank:AY785220.1] & [GenBank:AY772142.1] \\
\hline & & Wales1 & [GenBank:AF387275.1] & [GenBank:AF387228.1] \\
\hline & & 6TUR10 & [GenBank:AF387274.1] & [GenBank:AF387227.1] \\
\hline & & 6ALMSM5 & [GenBank:AF387271.1] & [GenBank:AF387224.1] \\
\hline & B. manjavacas & 5FUE1 & [GenBank:AF387261.2] & [GenBank:AF387216.1] \\
\hline & & 3CVF1 & [GenBank:AF387260.2] & [GenBank:AF387214.1] \\
\hline & & 5CAP2 & [GenBank:AF387259.2] & [GenBank:AF387217.1] \\
\hline & & 3MANL5 & [GenBank:AF387257.2] & [GenBank:AF387213.1] \\
\hline
\end{tabular}


Table 4 Characteristics of Brachionus species, including other Rotifera, used in this study and DNA sequence accession numbers (Continued)

$\begin{array}{cccc}\text { B. koreanus } & \text { Uljin1 } & \text { [GenBank:GU987061] } & \text { [GenBank:GU987073] } \\ \text { Taean } & \text { [GenBank:GU987062] } & \text { [GenBank:GU987074] } \\ \text { Daesan } & \text { [GenBank:GU987063] } & \text { [GenBank:GU987075] } \\ \text { Okgu } & \text { [GenBank:GU987067] } & \text { [GenBank:GU987079] } \\ \text { Uljin2 } & \text { [GenBank:GU987068] } & \text { [GenBank:GU987080] }\end{array}$

used these six specific regions for rapid identification of Brachionus rotifers before and successfully accomplished an unambiguous species identification. Thus, a multiplex PCR method would be a proper congruent for species with ambiguous morphological characteristics.

Mitochondrial $\mathrm{CO} 1$ and nuclear rDNA sequences are useful in molecular systematics to estimate genetic diversity and phylogenetic relationships between taxa (Kellogg et al. 1996). Nuclear rDNAs were delineating higher taxon levels, e.g., families and orders due to the high level of conservation among these sequences. In contrast, ITS regions are considered to be useful in defining interspecific differences, as they are less subject to functional constraints and would evolve more rapidly. Therefore, we investigated rotifer phylogeny using ITS1 along with the CO1 gene from the rotifer genus Brachionus. Using CO1 and ITS1, we reconstructed a phylogenetic tree of six species belonging to the genus Brachionus.

The mitochondrial CO1 and rDNA ITS have only a few evolutionary constraints, and they are expected to evolve at or near a neutral level (Bakker et al. 1995). Molecular
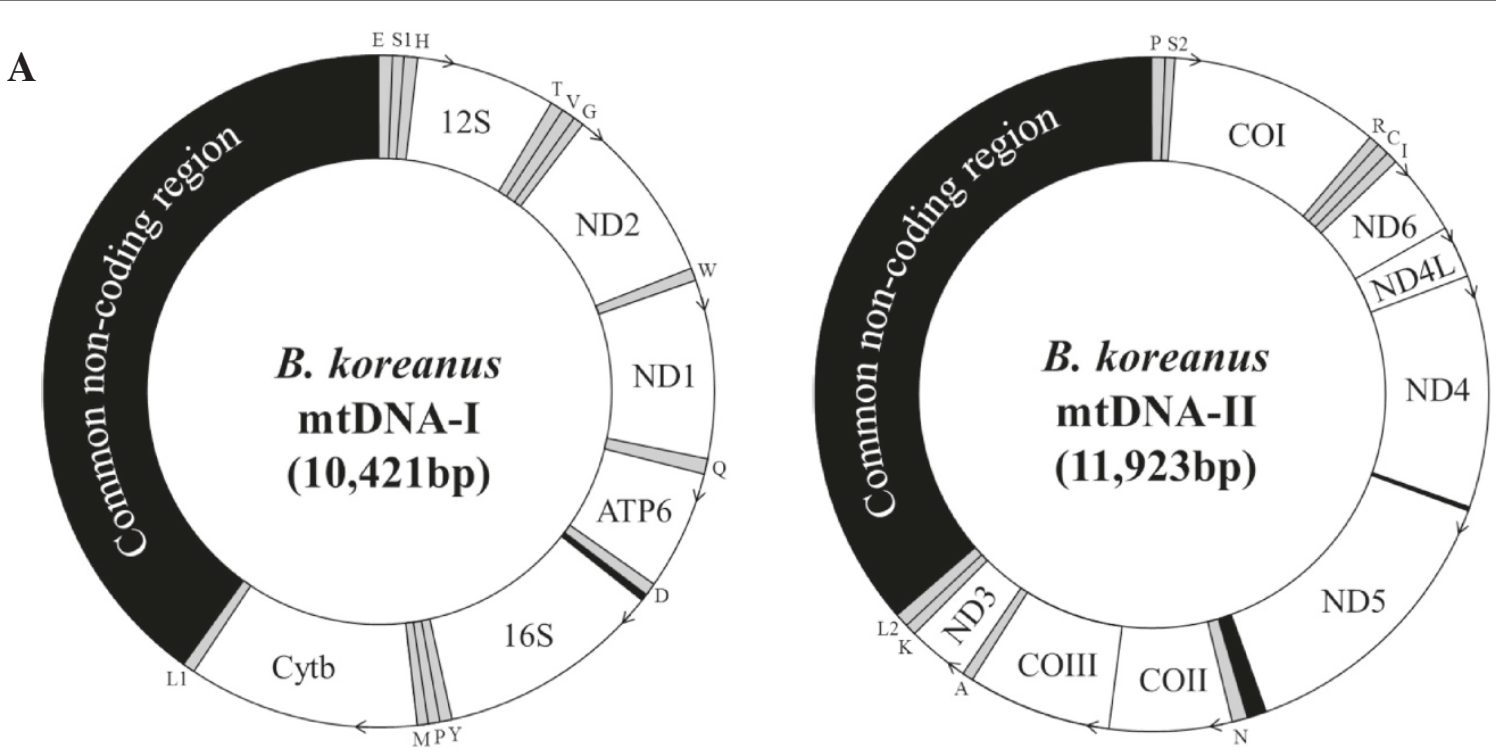

B

Brachionusplicatilis

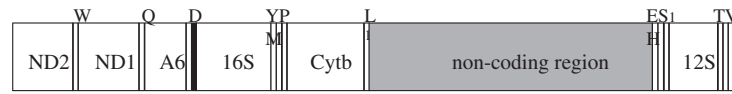

\section{Brachionuskoreanus}
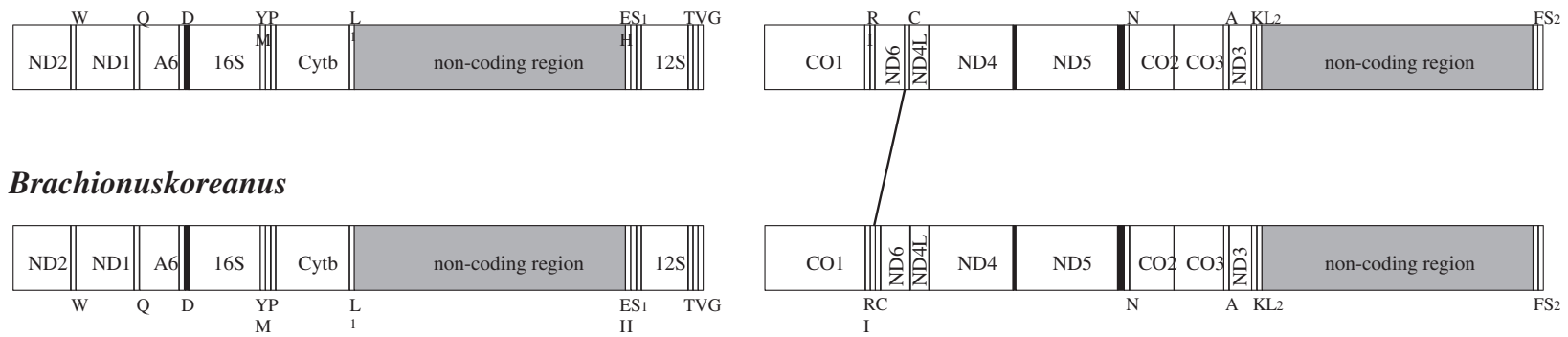

Figure 6 Gene organization of two mitochondrial genomes of the rotifers B. plicatilis and B. koreanus sp. nov. (A) Two circular mitochondrial genomes from $B$. koreanus sp. nov. One-letter abbreviations of amino acids are used to label the corresponding tRNA genes. (B) The thick line between pairs of mitogenomes between B. plicatilis and B. koreanus sp. nov. represents translocation. Modified from Hwang et al. (2013). 
analyses revealed that individuals of Brachionus populations originating from the same localities had nearly identical genotypes. To get a cue about large-scale biogeographic intraspecific variation, we investigated CO1-ITS1 sequences of 45 Brachionus populations collected from geographically areas as disjunct as Korea, China, and Japan as well as CO1-ITS1 sequences from GenBank (Figure 1). Molecular analyses of the geographic samples showed that $\mathrm{CO}$ sequences were quite different between these populations (Figure 4).

We sequenced the complete mitochondrial genome from the rotifer B. koreanus, which consisted of two circular forms of mitochondrial DNA (Figure 6A). When comparing the mitochondrial DNA of $B$. koreanus with those of its supposedly closest related species, B. plicatilis (Figure 6B), the mitochondrial organization was almost identical. The single rearrangement of $t R N A$-Cys between $t R N A$-arg and $t R N A$-ile indicated that the mitogenome rearrangement occurred in the closest related congeneric species with concerted evolution. We assume that among cryptic species, such as rotifers, the analysis of the complete mitochondrial genome will provide a suitable instrument for the characterization of population differences.

\section{Conclusions}

Care must be taken in the choice of characters since the discriminating power of a morphometric approach sensitively depends on the measured characters. Data obtained from clones cultivated at laboratory conditions need to be corroborated with populations from the field as well. As there are other and new species within Brachionus awaiting description, detailed comparisons are possible for meaningful systematic research within this morphologically variable genus. By distinguishing and characterizing different clones within five conspecifics within the Brachionus complex, our analysis bridged the gap between the classical taxonomy of rotifers and modern approaches. Our results show that morphometry can provide a powerful tool to differentiate similar species in addition to molecular, ecological, and physiological data.

\section{Competing interests}

The authors declare that they have no competing interests.

\section{Authors' contributions}

DSH carried out allometry and molecular genetic studies and initially drafted the manuscript. HUD carried out the drawing of a rotifer and participated in the making of the draft. HGP participated in the collection of rotifers and initially maintained them in the aquarium. JSL conceived the study and participated in its design and coordination. All authors read and approved the final manuscript.

\section{Acknowledgments}

This work was supported by a grant from the National Research Foundation (2012R1A1A2000970) funded to Jae-Seong Lee and also was supported by a grant from NRF (2012-R1A2A2A02012617).

\section{Author details}

'Department of Molecular and Environmental Bioscience, Graduate School, Hanyang University, Seoul 133-791, South Korea. ${ }^{2}$ Department of Life Science, College of Natural Sciences, Sangmyung University, Seoul 110-743, South Korea. ${ }^{3}$ Faculty of Marine Bioscience and Technology, College of Life Sciences, Kangnung-Wonju National University, Gangneung 210-702, South Korea. ${ }^{4}$ Department of Chemistry, College of Natural Sciences, Hanyang University, Seoul 133-791, South Korea.

Received: 10 June 2013 Accepted: 5 September 2013

Published: 23 September 2013

\section{References}

Bakker FT, Olsen J, Stam WT (1995) Evolution of nuclear rDNA ITS sequences in the Cladophora albida/sericea clade (Chlorophyta). J Mol Evol 40:640-651

Chullasorn S, Dahms H-U, Schizas NV, Kangtia P (2009) Phylogenetic inferences of Tisbe Lilljeborg, 1853 (Copepoda, Harpacticoida) with Tisbe thailandensis sp. nov. from Thailand. Hydrobiologia 627:1-17

Ciros-Pérez J, Carmona MJ, Serra M (2001) Resource competition between sympatric sibling rotifer species. Limnol Oceanogr 46:1511-1523

Dahms H-U, Hagiwara A, Lee J-S (2011) Ecotoxicology, ecophysiology, and mechanistic studies with rotifers. Aquat Toxicol 101:1-12

Fu Y, Hirayama K, Natsukari Y (1991) Morphological differences between two types of the rotifer Brachionus plicatilis O.F. Müller. J Exp Mar Biol Ecol 151:29-41

Gómez A, Snell TW (1996) Sibling species and cryptic speciation in the Brachionus plicatilis species complex (Rotifera). J Evol Biol 9:953-964 Hagiwara A, Kotani T, Snell TW, Assava-Aree M, Hirayama K (1995) Morphology, reproduction, genetics, and mating behavior of small, tropical marine Brachionus strains (Rotifera). J Exp Mar Biol Ecol 194:25-37

Huelsenbeck JP, Ronquist F (2001) MRBAYES: Bayesian inference of phylogenetic trees. Bioinformatics 17:754-755

Hwang D-S, Suga K, Sakakura Y, Hagiwara A, Park HG, Rhee J-S, Lee J-S (2013) Complete mitochondrial genome of the monogonont rotifer, Brachionus koreanus (Rotifera: Brachionidae). Mitochondrial DNA, in press

Kellogg EA, Appels R, Mason-Gamer RJ (1996) When genes tell different stories: the diploid genera of Triticeae (Gramineae). Syst Bot 21:231-247

Lubzens E, Zmoa O, Barr Y (2001) Biotechnology and aquaculture of rotifers. Hydrobiologia 446/447:337-353

Min GS, Park JK (2009) Eurotatorian paraphyly: revisiting phylogenetic relationships based on the complete mitochondrial genome sequence of Rotaria rotatoria (Bdelloidea: Rotifera: Syndermata). BMC Genomics 10:533

Segers H (1995) Nomenclature consequences of some recent studies on Brachionus plicatilis (Rotifera, Brachionidae). Hydrobiologia 313/314:121-122

Serra M, Gómez A, Carmona MJ (1998) Ecological genetics of Brachionus sympatric sibling species. Hydrobiologia 387/388:373-384

Snell TW, Janssen CR (1995) Rotifers in ecotoxicology: a review. Hydrobiologia 313/314:231-247

Sokal RR, Rohlf FJ (1969) Biometry. Freeman, New York

Steinauer ML, Nickol BB, Orti G (2007) Cryptic speciation and patterns of phenotypic variation of variable acanthocephalan parasite. Mol Ecol 16:4097-4109

Sudzuki M (1987) Intraspecific variability of Brachionus plicatilis. Hydrobiologia 147:45-47

Suga K, Mark Welch DB, Tanaka Y, Sakakura Y, Hagiwara A (2008) Two circular chromosomes of unequal copy number make up the mitochondrial genome of the rotifer Brachionus plicatilis. Mol Biol Evol 25:1129-1137

Thompson JD, Higgins DG, Gibson TJ (1994) CLUSTAL W: improving the sensitivity of progressive multiple sequence alignment through sequence weighting, position-specific gap penalties and weight matrix choice. Nucleic Acids Res 22:4673-4680

Vasileiadou K, Papakostas S, Triantafyllidis A, Kappas I, Abatzopoulos TJ (2009) A multiplex PCR method for rapid identification of Brachionus rotifers. Mar Biotechnol 11:53-61

Walker KF (1981) A synopsis of ecological information on the saline lake rotifer Brachionus plicatilis Müller 1786. Hydrobiologia 81:159-167

\section{doi:10.1186/1810-522X-52-13}

Cite this article as: Hwang et al:: A new intertidal Brachionus and intrageneric phylogenetic relationships among Brachionus as revealed by allometry and CO1-ITS1 gene analysis. Zoological Studies 2013 52:13. 